\title{
Timing of surgery in thoracolumbar trauma: is early intervention safe?
}

\author{
Christopher Paul O’Boynick, M.D., ${ }^{1}$ Mark F. Kurd, M.D., ${ }^{2}$ Bruce V. Darden II, M.D., ${ }^{2}$ \\ Alexander R. Vaccaro, M.D., Ph.D., ${ }^{3}$ and Michael G. Fehlings, M.D., Ph.D., F.R.C.S.C. ${ }^{4}$ \\ ${ }^{1}$ Department of Orthopaedics, Saint Louis University, St. Louis, Missouri; ${ }^{2}$ OrthoCarolina Spine Center, \\ Orthopaedic Surgery, Charlotte, North Carolina; ${ }^{3}$ Thomas Jefferson University Hospital, Rothman Institute, \\ Philadelphia, Pennsylvania; and ${ }^{4}$ Department of Neurosurgery, University of Toronto, Ontario, Canada
}

\begin{abstract}
The understanding of the optimal surgical timing for stabilization in thoracolumbar fractures is severely limited. Thoracolumbar spine fractures can be devastating injuries and are often associated with significant morbidity and mortality. The role of early surgical stabilization (within 48-72 hours of injury) as a vehicle to improve outcomes in these patients has generated significant interest. Goals of early stabilization include improved neurological recovery, faster pulmonary recovery, improved pain control, and decreased health care costs. Opponents cite the potential for increased bleeding, hypotension, and the risk of further cord injury as a few factors that weigh against early stabilization. The concept of spinal cord injury and its relationship to surgical timing remains in question. However, when neurological outcomes are eliminated from the equation, certain measures have shown positive influences from prompt surgical fixation.

Early fixation of thoracolumbar spine fractures can significantly decrease the duration of hospital stay and the number of days in the intensive care unit. Additionally, prompt stabilization can reduce rates of pulmonary complications. This includes decreased rates of pneumonia and fewer days on ventilator support. Cost analysis revealed as much as $\$ 80,000$ in savings per patient with early stabilization. All of these benefits come without an increase in morbidity or evidence of increased mortality. In addition, there is no evidence that early stabilization has any ill effect on the injured or uninjured spinal cord. Based on the existing data, early fixation of thoracolumbar fractures has been linked with positive outcomes without clear evidence of negative impacts on the patient's neurological status, associated morbidities, or mortality. These procedures can be viewed as "damage control" and may consist of simple posterior instrumentation or open reductions with internal fixation as indicated. Based on the current literature it is advisable to proceed with early surgical stabilization of thoracolumbar fractures in a well-resuscitated patient, unless extenuating medical conditions would prevent it.

(http://thejns.org/doi/abs/10.3171/2014.5.FOCUS1473)
\end{abstract}

KEY WordS • thoracolumbar • trauma • timing • early

$\mathrm{S}$ PINE fractures comprise an estimated $6 \%$ of all fractures worldwide. ${ }^{12}$ The thoracic and lumbar spinal segments are most commonly involved, with an estimated incidence of 700,000 fractures each year. ${ }^{46}$ The thoracolumbar segment composed of T10-L2 accounts for more than half of these fractures, with the lower lumbar spine and upper thoracic spine accounting for $32 \%$ and $16 \%$, respectively. ${ }^{22}$

The role of early surgical stabilization and resultant early mobilization as a method to reduce morbidity and mortality associated with these fractures has sparked significant interest. Surmised benefits of early stabilization include improved neurological recovery, improved

\footnotetext{
Abbreviations used in this paper: $\mathrm{ICU}=$ intensive care unit; $\mathrm{LOS}$ $=$ length of stay; $\mathrm{PLC}=$ posterior ligamentous complex; $\mathrm{SCI}=$ spinal cord injury; TLICS $=$ Thoracolumbar Injury Classification and Severity Score.
}

pulmonary function, reduced pain with mobilization, decreased intensive care unit (ICU) length of stay (LOS), decreased hospital LOS, and decreased mortality. ${ }^{1}$

Early surgical intervention is not without its proposed drawbacks. These stabilization procedures can be complex and may aggravate preexisting systemic insult. ${ }^{27}$ They can be associated with increased hemorrhage, resultant hypotension, and the potential for a deleterious effect on the already injured spinal cord. Additionally, early intervention may put the surgeon at a disadvantage due to missed or underestimated associated injuries and operating in less than ideal conditions relative to the intricacy required of the surgical procedure. ${ }^{1}$

Add to this debate the role of early decompression for spinal cord injury (SCI), and the determination of optimal timing of surgical intervention for thoracolumbar trauma becomes quite convoluted.

It is the goal of this work to provide insight into the 


\section{P. O’Boynick et al.}

optimal timing for stabilization of thoracolumbar spine fractures. In addition, we hope to demonstrate the benefits of early stabilization in the patient with multiple injuries.

\section{Epidemiology}

Thoracolumbar fractures occur in a bimodal distribution, with an increased incidence in males $<30$ years of age, secondary to high-energy trauma, and as a sequela of osteoporosis in the geriatric population. ${ }^{19}$ With $>160,000$ injuries every year in North America alone, trauma to this transitional zone between the relatively fixed thoracic spine and the mobile lumbar spine can result in disastrous complications including pain, deformity, and loss of function (Table 1).13,30,36 Neurological injury can be found in up to $20 \%$ of thoracolumbar fractures. ${ }^{11}$ These highenergy fractures are often associated with other life- and limb-threatening injuries including trauma to the thoracic contents, great vessels, solid and hollow organs, and long bones. ${ }^{47}$ The complexities in these patients with multisystem involvement can make initial diagnosis difficult, with reported rates of missed injury as high as $20 \% .^{24}$ Long-term clinical results following stabilization are limited, with varying reported outcomes. McLain ${ }^{32}$ reported a return to full-time employment in $70 \%$ of surgically stabilized patients, with $16 \%$ unable to return to their heavyduty positions at 5 years. Krengel et al. ${ }^{28}$ reported far less impressive numbers, with only $36 \%$ of patients with incomplete neurological deficits returning to full-time work. Schouten et al. ${ }^{38}$ showed that patients with thoracic spine fractures without significant neurological injury (American Spinal Injury Association Grade D or E) had a return to work rate of nearly $90 \%$ and recovered a general health status not significantly different from population norms. However, in their study, increasing neurological deficit was associated with poorer outcomes, lower return to work, and increasing disability.

\section{Surgical Decision Making}

The majority of thoracolumbar spine fractures are stable and do not require surgery. Typical treatment requires adequate pain control, with or without an orthosis, and progress toward rehabilitation. Bracing time averages 10-12 weeks. Multiple studies have demonstrated treatment success with an external orthosis in stable thoracolumbar burst fractures, both alone and compared with surgical intervention. ${ }^{20,33,43,45}$ The goals of nonoperative

\section{TABLE 1: Epidemiology of thoracolumbar fractures}

700,000 fractures/yr worldwide
160,000 injuries/yr in North America
$52 \%$ of fractures at T10-L2
$32 \%$ of fractures at L3-5
$16 \%$ of fractures at T1-9
rates of missed injury up to $20 \%$
neurological injuries in up to $20 \%$ of cases
worse outcomes associated $w /$ increasing neurological deficit

management are identical to those of surgical intervention and must provide for spinal stability, deformity correction, neurological recovery, and pain control, and must allow for rehabilitation. ${ }^{42}$

Nonoperative patterns typically include simple compression fractures and stable burst fractures that lack involvement of the posterior ligamentous complex (PLC) in a neurologically intact patient. These patterns usually present with $<30^{\circ}$ of kyphosis across the injured segment and $<50 \%$ loss of height in the fractured vertebral body. The degree of canal compromise in the setting of normal neurological function is not an indication for surgery, and multiple studies have shown equivalent outcomes between operative and nonoperative management in this subgroup.45,49 Flexion-distraction or "chance" injuries can also be treated effectively in a brace if the disruption passes through mostly bony elements. ${ }^{47}$

Operative intervention in patients with thoracolumbar fractures has typically been reserved for unstable fractures, progressive neurological deficits, and patients unable to tolerate bracing. Contraindications for bracing can include obesity, skin lesions, visceral injury, multiple extremity injuries, and so on. ${ }^{46}$ Instability typically requires disruption of the anterior and middle columns as well as the PLC. This is routinely found in burst fractures demonstrating $>30^{\circ}$ of kyphosis as well as fracturedislocations and flexion-distraction injuries through predominantly soft-tissue elements. ${ }^{18}$

In an attempt to simplify and predict the need for surgical intervention, Vaccaro et al. ${ }^{41}$ introduced the Thoracolumbar Injury Classification and Severity Score (TLICS) in 2005. This classification scheme applied numerical values to fracture morphology, neurological status, and PLC injury, with a goal of predicting instability and the need for stabilization. Patients scoring $<4$ on this scale could be managed nonsurgically, whereas those scoring $>4$ required stabilization. Those patients scoring exactly 4 points were best left to the surgeon's discretion. This system has demonstrated excellent reliability and reproducibility as well as relatively simple application. ${ }^{34,44}$ Lenarz and Place $^{29}$ found $>80 \%$ agreement with previously managed patients at their institution when the scale was applied in a retroactive fashion. Although it is useful for determining a "yes" or "no" with regard to the need for surgical intervention, the TLICS does not address the temporality of fixation. This remains at the discretion of the treating physician.

\section{Surgical Timing}

The concept of optimal surgical timing in thoracolumbar fractures is still severely limited. It makes logical sense that the more quickly the neurological structures are decompressed the less severe the secondary damage may become. Unfortunately, this has not been borne out as clearly in the literature. ${ }^{39}$ Currently, the American Association of Neurological Surgeons recommends a mean arterial pressure of $85-90 \mathrm{~mm} \mathrm{Hg}$ for the first 7 days following injury, because this has been shown to improve neurological outcomes. ${ }^{2}$ However, our understanding of SCI pathophysiology remains limited. Current data sug- 
gest that white matter is more resilient and that damage remains reversible up to 72 hours after injury, compared with nearly instantaneous irreversible damage to the gray matter. ${ }^{23}$ Animal studies have suggested that early decompression (within 8 hours of injury) may have a neuroprotective benefit. ${ }^{10,15}$

Unfortunately, the human data remain more convoluted. Burke and Berryman ${ }^{4}$ and Hadley et al..$^{21}$ retrospectively demonstrated that timing of the reduction of cervical spine injuries was more important for neurological recovery than the method used for reduction. Vaccaro et al. ${ }^{40}$ published a prospective randomized clinical trial on cervical SCI and showed no neurological benefit to early surgery. More recently, another prospective trial examining SCI in thoracic fractures showed a nonsignificant trend toward neurological recovery with early surgical intervention. ${ }^{7}$ Most of the data regarding surgical timing in SCI are limited to the cervical spine. The thoracolumbar region represents a mélange of both upper and lower motor neurons, which may have different potentials for recovery, and this may limit the applicability of cervical SCI data.

If neurological recovery is eliminated as an outcome of interest with respect to timing of stabilization, certain measures have been shown to be influenced by the timing of surgery. ${ }^{6}$ Most of these data have come in the form of large retrospective analyses of databases. ${ }^{6,48}$ The outcomes showing influence from early surgical stabilization ( $<72$ hours) include hospital and ICU LOS, respiratory complications, morbidity, and mortality.

In a systematic review, Bellabarba et al. ${ }^{1}$ identified seven $^{7-9,25-27,37}$ studies reporting on hospital LOS and ICU LOS. Across all of these studies hospital LOS was significantly decreased with early surgical stabilization. The ICU LOS was also decreased significantly in these studies, but the effect was limited only to early thoracic fixation. There was no reported decrease in ICU LOS in early surgical stabilization of thoracolumbar fractures. ${ }^{7,8}$ Xing et al. ${ }^{48}$ more recently reviewed 9 studies, including 2 studies $^{3,17}$ not available to Bellabarba et al., and also found that hospital LOS was significantly lower in patients receiving early stabilization.

Early fixation may minimize pulmonary complications. Decreased duration of ventilator support has been shown to correlate with fixation within 72 hours of admission. ${ }^{10,18,28,37}$ Kerwin et al. ${ }^{26}$ reported fewer ventilator days in the early surgical group with SCI, along with a more pronounced effect in patients with thoracic fractures. Comparison of numbers of ventilator days indicated that patients without SCI did not benefit from early stabilization. $^{25,26}$ Two authors reported significantly decreased rates of pneumonia with early fixation. ${ }^{9,26}$ Schinkel et al. ${ }^{37}$ found that early fixation decreased rates of pulmonary failure from $31 \%$ to $19 \%$. Early fixation of thoracolumbar and lumbar fractures demonstrated no beneficial effect with respect to pulmonary complications.,.$^{9,25-27}$

Reported mortality rates in early versus late stabilization of thoracolumbar fractures are highly variable. Two underpowered studies using overlapping data have reported trends toward increased mortality with early stabilization, but these did not reach significance..$^{25,26}$
This trend was investigated further by the same group on a larger scale, and no difference was found in mortality among 871 score-matched patients when stratified by stabilization before and after 72 hours. ${ }^{27}$ Early fixation has been reported by Schinkel et al. ${ }^{37}$ to statistically decrease mortality in thoracic fractures. Their study also stratified their results based on the Injury Severity Scale and continued to show a protective benefit from early stabilization across increasing injury severity. Data regarding thoracolumbar and lumbar fractures have shown no difference in mortality based on timing of surgical fixation. ${ }^{9,25-27}$

Cost-effectiveness of early fixation has also been an area of interest in the treatment of thoracolumbar trauma. Three studies have specifically addressed the costs associated with early versus late surgical fixation. ${ }^{3,9,27}$ Boakye et al. ${ }^{3}$ reported a nearly $\$ 40,000$ decrease of in-hospital charges for patients receiving early fixation. In a study of 79 thoracic fractures in which 30 were treated with early fixation, Croce et al..$^{9}$ demonstrated a savings of $>$ $\$ 60,000$ per patient treated with early fixation. Finally, Kerwin et al. ${ }^{27}$ identified an almost $\$ 80,000$ difference in hospital-associated charges between early and late fixation in thoracic fractures. None of these studies uncovered a difference in cost-effectiveness based on timing of lumbar fracture fixation.

\section{Illustrative Cases}

\section{Case 1}

This 39-year-old truck driver was in a motor vehicle accident. The patient was restrained and did not lose consciousness. He complained of severe back pain. The patient was found to be neurovascularly intact in the upper and lower extremities. Admission CT scans of the lumbar spine (Fig. 1) demonstrated a flexion-distraction fracture of L-1 that involved the right L-1 pedicle. The MRI studies of the lumbar spine (Fig. 2) demonstrated disruption of the PLC at T12-L1. The TLICS was as follows: morphology (distraction) 4 points, neurological involvement (intact) 0 points, PLC (injured) 3 points. The patient was taken to surgery within 24 hours of his injury for a T10L2 posterior instrumented fusion (Fig. 3). The patient tolerated the procedure well and was discharged from the hospital on postoperative Day 3 in a thoracolumbar spinal orthosis.

\section{Case 2}

This 28-year-old unrestrained driver was in a motor vehicle accident. The patient was ejected from the automobile and was found unconscious. On arrival at the trauma center, the patient was noted to have $4 / 5$ motor strength bilaterally in his lower extremities in all muscle groups. His sensation to light touch was intact in his bilateral lower extremities. Results of the remainder of his neurological examination were normal. Admission CT scans (Fig. 4) demonstrated an L-1 burst fracture with > $50 \%$ spinal canal compromise. The TLICS was as follows: morphology (burst) 2 points, neurological involvement (incomplete) 3 points, PLC (intact) 0 points. The 

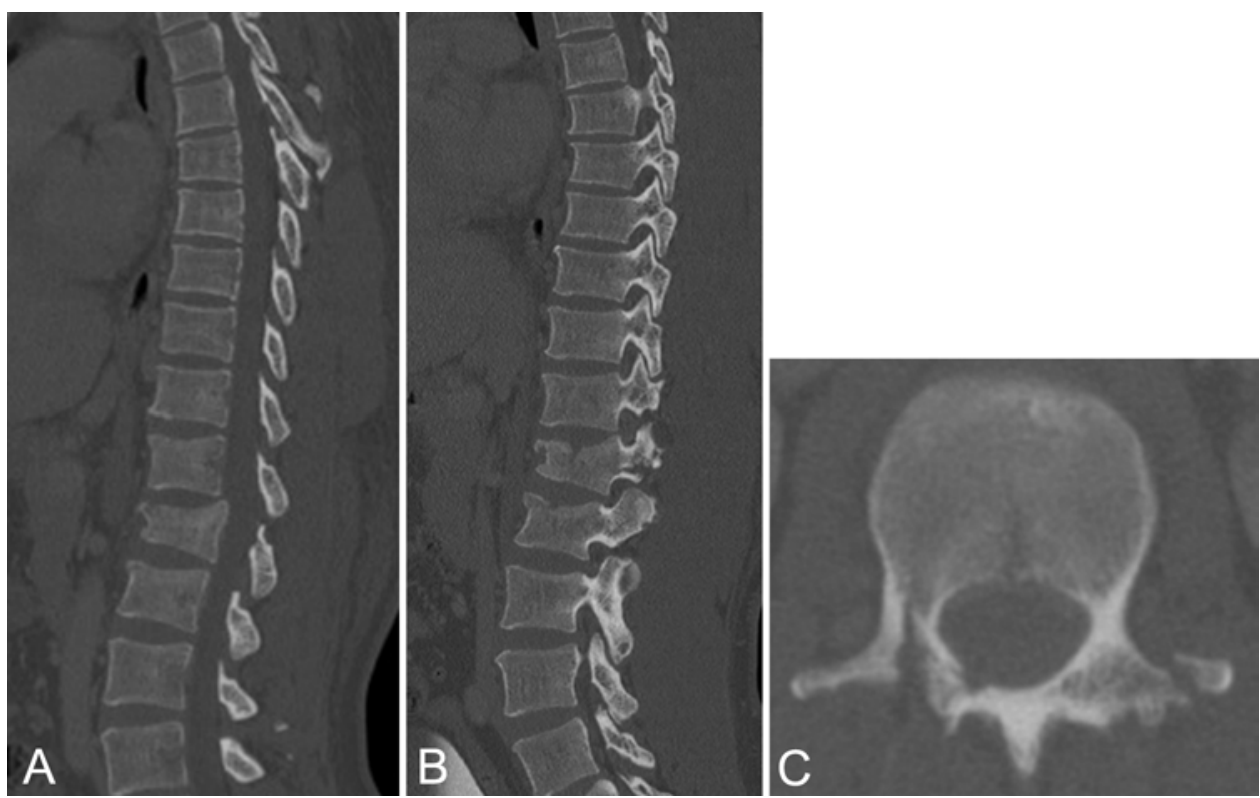

FIG. 1. Case 1. A: Midsagittal CT scan demonstrating compression of the L-1 vertebral body and resulting kyphosis across the involved segments. B: Right parasagittal CT scan demonstrating local kyphosis and involvement of the anterior, middle, and posterior columns at L-1. C: Axial CT scan of L-1 showing pedicle involvement.

patient was taken to the operating room for an L-1 corpectomy with cage placement and T12-L2 instrumented fusion (Fig. 5) within 24 hours of admission. He regained full function postoperatively.

\section{Discussion}

Timing of stabilization in the setting of thoracolumbar spine fracture remains controversial. There are very few prospective studies examining outcomes related to the timing of surgery, limited obviously by the reality of a randomized controlled trial of injured patients. Most of the available data come from retrospective analysis of databases. ${ }^{48}$

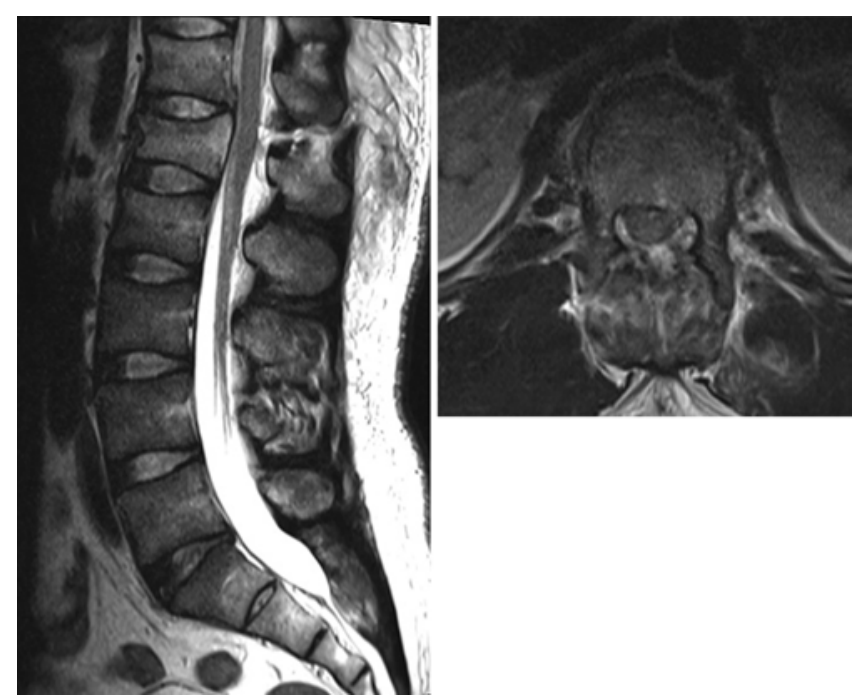

FIG. 2. Case 1. Left: Sagittal MRI study demonstrating involvement of the PLC. Right: Axial MRI scan at T12-L1 showing PLC involvement.
Advocates of early fixation cite basic science and animal studies outlining definitive evidence that early decompression improves neurological outcomes. ${ }^{5,10}$ This proposed link between early decompression and improved neurological outcomes has not been as evident in some of the clinical studies. ${ }^{40}$ Nevertheless, the more recent results of the ongoing Surgical Treatment of Acute Spinal Cord Injury Study (STASCIS) do suggest that early ( $<24$ hours) decompression of cervical SCI may provide improved neurological recovery and decreased complications at 1 year. ${ }^{16}$ Unfortunately, most of these data on early decompression in either direction are limited to cervical SCI and may
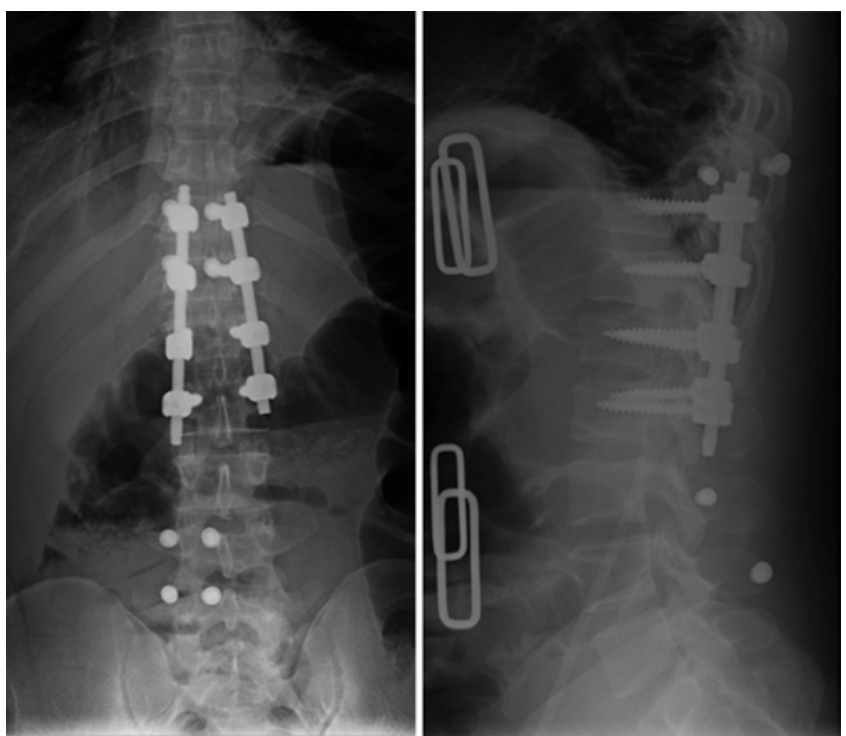

FIG. 3. Case 1. Left: Postoperative anteroposterior radiograph showing instrumented posterior spinal fusion from T-10 to L-2. Right: Postoperative lateral radiograph demonstrating T10-L2 instrumented posterior spinal fusion. 

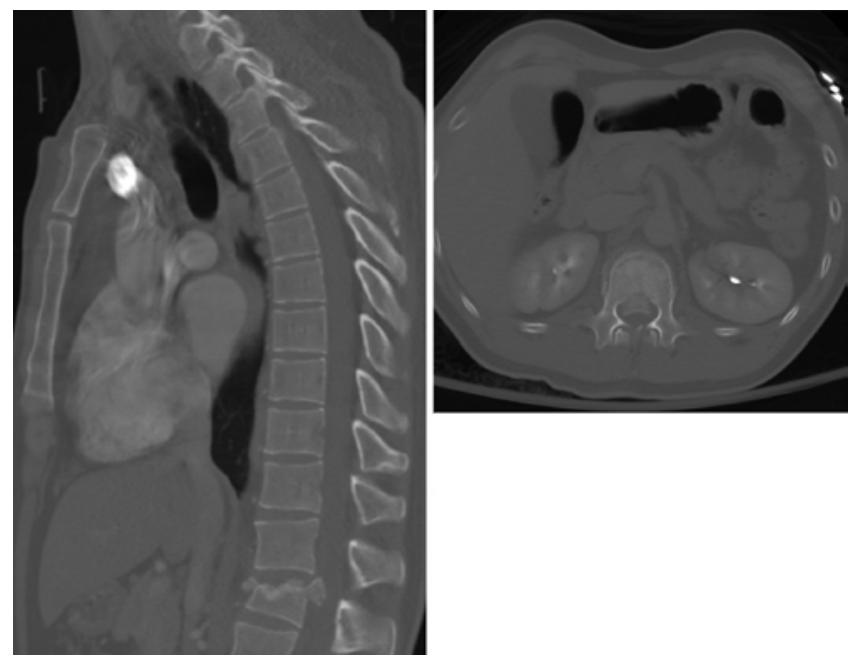

FIG. 4. Case 2. Left: Midsagittal CT scan showing L-1 burst fracture with $>50 \%$ canal compromise and local kyphosis. Right: Axial CT scan showing L-1 burst fracture with $>50 \%$ canal compromise.

have limited applicability to the thoracolumbar spine due to physiological and anatomical differences.

Interestingly, a survey of 2000 neurosurgeons showed that approximately $80 \%$ supported early fixation, but less than half of this group found it feasible within 24 hours of admission. ${ }^{14}$ They attributed this disagreement to a perceived or actual lack of the resources necessary for early fixation overnight and on weekends. This opinion may have some clinical basis; Macias et al. ${ }^{31}$ found that the risk of long-term paralysis was decreased by $33 \%$ if a patient was treated at a trauma center, and that a positive correlation in patient outcomes was associated with high surgical volume at the treating institution. This may indicate that facilities that have the resources necessary to treat this volume of patients may also have the necessary resources to treat these injuries in an early fashion.

Opponents of early surgical stabilization express concerns about possible injury to an already traumatized cord. Later surgery minimizes the potential for missed injuries and underestimation of associated injuries, and allows maximal patient resuscitation prior to surgical intervention. ${ }^{48}$ However, data identifying a detriment to neurological outcomes with early fixation are absent from the literature.

As mentioned earlier, the elimination of neurological outcomes in the debate about surgical timing brings about some interesting results. Three studies identified a cost savings ranging from $\$ 40,000$ to $\$ 80,000$ per patient. . $^{3,9,27}$ Xing et al. ${ }^{48}$ identified 9 articles citing a reduction in hospital LOS with early stabilization of thoracolumbar fractures. In addition to a reduction in hospital LOS, early fixation tended to reduce thromboembolic complications, pulmonary complications, and ventilator days. ${ }^{3,7-9,25,28,37}$ This early surgical fixation appears to come without any significant increase in mortality, as Kerwin and colleagues identified in their series of 3 papers. ${ }^{25-27}$

Based on the existing data, early fixation of thoracolumbar fractures has been linked to positive outcomes without clear evidence of negative impacts on the patient's neurological status, associated morbidities, or mortality. The majority of these nonneurological benefits appear to be limited mostly to thoracic spine fractures, but there is no clear evidence against early fixation in the thoracolumbar and lumbar spine. Most of the data regarding early decompression in SCI come from the cervical spine and remain controversial. However, no evidence present-
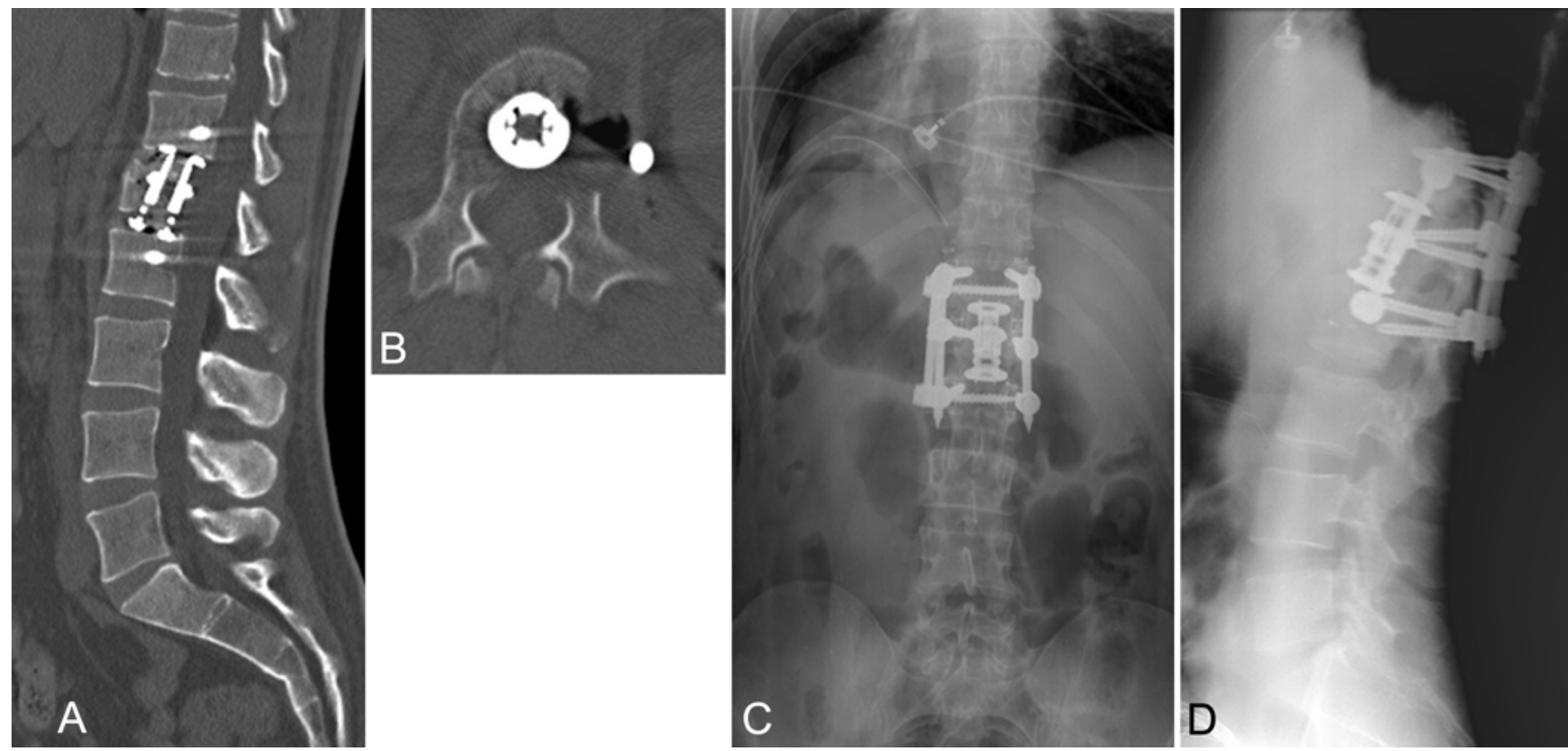

FIG. 5. Case 2. A: Postoperative midsagittal CT scan demonstrating the decompression at L-1 and the return of lordosis across the involved segments. B: Postoperative axial CT scan showing anterior instrumentation and significant improvement in canal compromise. C: Postoperative anteroposterior radiograph revealing the completed anterior and posterior construct. D: Postoperative lateral radiograph showing the completed construct. 


\section{P. O’Boynick et al.}

ed here suggests that early decompression puts the neural elements at any greater risk. Early stabilization may not always convey a benefit in patients with thoracolumbar fractures, but early fixation in a well-resuscitated patient appears to be without significant risk.

Although assessment of adequate resuscitation prior to surgical intervention is still at the discretion of the treating physician, several markers have been suggested to aid in clinical decision making. Traditionally, end points for shock included normalized blood pressure, heart rate, and urine output. However, in the setting of compensated shock these values may appear normal in an inadequately resuscitated patient. Porter and Ivatury ${ }^{35}$ reviewed available measureable end points of resuscitation in patients with compensated shock and concluded that serum lactate (normal $<2 \mathrm{mmol} / \mathrm{L}$ ), base deficit (normal -2 to +2 ), and gastric mucosal pH (normal 7.30-7.35) were excellent indicators of resuscitation. Whereas these authors recommend correction of at least one if not all of these markers within 24 hours of injury, it would seem that correction of these markers prior to surgical intervention should take place as well.

Although early fixation may best be performed at dedicated trauma centers that have the resources to manage these complex patients, this may not always be an option and treating surgeons should be prepared to intervene.

\section{Conclusions}

In patients with major thoracolumbar trauma it is advisable to proceed with early surgical stabilization within 48 hours unless extenuating medical conditions would prevent it. Similar to the application of external fixators in long-bone fractures, the theory of "damage control" stabilization in the patient with multiple traumas may be applied to the spine. These procedures can be simple posterior stabilizations or open reductions with internal fixation, and they can be combined with staged anterior procedures as necessary. These principles are exemplified in the Illustrative Cases section.

\section{Disclosure}

Dr. Darden is a consultant for and also receives royalties from Stryker, and he has direct stock ownership in BioMedFlex. Dr. Vaccaro is a board member for AO Spine, Innovative Surgical Design, Association of Collaborative Spine Research, and Spinicity. He is a consultant for Gerson Lehman Group, Guidepoint Global, Medacorp, Stout Medical, Innovative Surgical Design, and Orthobullets. He receives grants or has grants pending from Stryker Spine, Cerapedics, and NuVasive. He receives royalties from DePuy, Medtronic, Stryker Spine, Biomet Spine, Globus, NuVasive, and Aesculap. He has direct stock ownership in Replication Medica, Globus, K-2 Medical, Paradigm Spine, Stout Medical, Spine Medica, Computational Biodynamics, Progressive Spinal Technologies, Spinology, Small Bone Innovations, Cross Current, Syndicom, In Vivo, Flagship Surgical, Advanced Spinal Intellectual Properties, Cytonics, Bonovo Orthopaedics, Electrocore, Gamma Spine, Location Based Intelligence, FlowPharma, R.S.I., Rothman Institute and Related Properties, Innovative Surgical Design, and Spinicity.

Author contributions to the study and manuscript preparation include the following. Conception and design: Kurd, Darden,
Vaccaro, Fehlings. Acquisition of data: O'Boynick. Analysis and interpretation of data: O'Boynick. Drafting the article: O'Boynick, Kurd, Darden, Fehlings. Critically revising the article: all authors. Reviewed submitted version of manuscript: all authors. Approved the final version of the manuscript on behalf of all authors: O’Boynick.

\section{References}

1. Bellabarba C, Fisher C, Chapman JR, Dettori JR, Norvell DC: Does early fracture fixation of thoracolumbar spine fractures decrease morbidity or mortality? Spine (Phila Pa 1976) 35 (9 Suppl):S138-S145, 2010

2. Blood pressure management after acute spinal cord injury. Neurosurgery 50 (3 Suppl):S58-S62, 2002

3. Boakye M, Arrigo RT, Hayden Gephart MG, Zygourakis CC, Lad S: Retrospective, propensity score-matched cohort study examining timing of fracture fixation for traumatic thoracolumbar fractures. J Neurotrauma 29:2220-2225, 2012

4. Burke DC, Berryman D: The place of closed manipulation in the management of flexion-rotation dislocations of the cervical spine. J Bone Joint Surg Br 53:165-182, 1971

5. Carlson GD, Gorden CD, Oliff HS, Pillai JJ, LaManna JC: Sustained spinal cord compression: part I: time-dependent effect on long-term pathophysiology. J Bone Joint Surg Am 85-A: 86-94, 2003

6. Carreon LY, Dimar JR: Early versus late stabilization of spine injuries: a systematic review. Spine (Phila Pa 1976) 36:E727E733, 2011

7. Cengiz SL, Kalkan E, Bayir A, Ilik K, Basefer A: Timing of thoracolomber spine stabilization in trauma patients; impact on neurological outcome and clinical course. A real prospective (rct) randomized controlled study. Arch Orthop Trauma Surg 128:959-966, 2008

8. Chipman JG, Deuser WE, Beilman GJ: Early surgery for thoracolumbar spine injuries decreases complications. J Trauma 56:52-57, 2004

9. Croce MA, Bee TK, Pritchard E, Miller PR, Fabian TC: Does optimal timing for spine fracture fixation exist? Ann Surg 233:851-858, 2001

10. Delamarter RB, Sherman J, Carr JB: Pathophysiology of spinal cord injury. Recovery after immediate and delayed decompression. J Bone Joint Surg Am 77:1042-1049, 1995

11. Denis F: The three column spine and its significance in the classification of acute thoracolumbar spinal injuries. Spine (Phila Pa 1976) 8:817-831, 1983

12. DeWald RL: Burst fractures of the thoracic and lumbar spine. Clin Orthop Relat Res (189):150-161, 1984

13. Diaz JJ Jr, Cullinane DC, Altman DT, Bokhari F, Cheng JS, Como J, et al: Practice management guidelines for the screening of thoracolumbar spine fracture. J Trauma 63:709-718, 2007

14. Fehlings MG, Rabin D, Sears W, Cadotte DW, Aarabi B: Current practice in the timing of surgical intervention in spinal cord injury. Spine (Phila Pa 1976) 35 (21 Suppl):S166-S173, 2010

15. Fehlings MG, Tator $\mathrm{CH}$ : An evidence-based review of decompressive surgery in acute spinal cord injury: rationale, indications, and timing based on experimental and clinical studies. J Neurosurg 91 (1 Suppl):1-11, 1999

16. Fehlings MG, Vaccaro A, Aarabi B, Shaffrey C, Dvorak M, Fisher C, et al: One year outcomes of the STASCIS study: a prospective, multicenter trial to evaluate the role and timing of decompression in patients with cervical spinal cord injury. J Neurosurg 110:A1044, 2009 (Abstract)

17. Frangen TM, Ruppert S, Muhr G, Schinkel C: The beneficial effects of early stabilization of thoracic spine fractures depend on trauma severity. J Trauma 68:1208-1212, 2010

18. Garfin SR, Blair B, Eismont FJ, Abitol JJ: Thoracic and upper lumbar spine injuries, in Browner BD, Jupiter JB, Levine AM, 
et al (eds): Skeletal Trauma: Fractures, Dislocations, Ligamentous Injuries, ed 2. Philadelphia: WB Saunders, 1998, Vol 1, pp 947-1034

19. Gertzbein SD: Scoliosis Research Society. Multicenter spine fracture study. Spine (Phila Pa 1976) 17:528-540, 1992

20. Gnanenthiran SR, Adie S, Harris IA: Nonoperative versus operative treatment for thoracolumbar burst fractures without neurologic deficit: a meta-analysis. Clin Orthop Relat Res 470:567-577, 2012

21. Hadley MN, Fitzpatrick BC, Sonntag VK, Browner CM: Facet fracture-dislocation injuries of the cervical spine. Neurosurgery 30:661-666, 1992

22. Harbrecht BG, Djurasovic M: Thoracolumbar spine trauma: diagnostic and therapeutic considerations for the general surgeon. Am Surg 75:191-196, 2009

23. Harrop JS, Sharan A, Ratliff J: Central cord injury: pathophysiology, management, and outcomes. Spine J 6 (6 Suppl): 198S-206S, 2006

24. Keene JS: Radiographic evaluation of thoracolumbar fractures. Clin Orthop Relat Res (189):58-64, 1984

25. Kerwin AJ, Frykberg ER, Schinco MA, Griffen MM, Arce CA, Nguyen TQ, et al: The effect of early surgical treatment of traumatic spine injuries on patient mortality. J Trauma 63:1308-1313, 2007

26. Kerwin AJ, Frykberg ER, Schinco MA, Griffen MM, Murphy T, Tepas JJ: The effect of early spine fixation on non-neurologic outcome. J Trauma 58:15-21, 2005

27. Kerwin AJ, Griffen MM, Tepas JJ III, Schinco MA, Devin T, Frykberg ER: Best practice determination of timing of spinal fracture fixation as defined by analysis of the National Trauma Data Bank. J Trauma 65:824-831, 2008

28. Krengel WF III, Anderson PA, Henley MB: Early stabilization and decompression for incomplete paraplegia due to a thoracic-level spinal cord injury. Spine (Phila Pa 1976) 18: 2080-2087, 1993

29. Lenarz CJ, Place HM: Evaluation of a new spine classification system, does it accurately predict treatment? J Spinal Disord Tech 23:192-196, 2010

30. Levine AM, McAfee PC, Anderson PA: Evaluation and emergent treatment of patients with thoracolumbar trauma. Instr Course Lect 44:33-45, 1995

31. Macias CA, Rosengart MR, Puyana JC, Linde-Zwirble WT, Smith W, Peitzman AB, et al: The effects of trauma center care, admission volume, and surgical volume on paralysis after traumatic spinal cord injury. Ann Surg 249:10-17, 2009

32. McLain RF: Functional outcomes after surgery for spinal fractures: return to work and activity. Spine (Phila Pa 1976) 29:470-477, 2004

33. Mumford J, Weinstein JN, Spratt KF, Goel VK: Thoracolumbar burst fractures. The clinical efficacy and outcome of nonoperative management. Spine (Phila Pa 1976) 18:955-970, 1993

34. Patel AA, Vaccaro AR, Albert TJ, Hilibrand AS, Harrop JS, Anderson DG, et al: The adoption of a new classification system: time-dependent variation in interobserver reliability of the thoracolumbar injury severity score classification system. Spine (Phila Pa 1976) 32:E105-E110, 2007

35. Porter JM, Ivatury RR: In search of the optimal end points of resuscitation in trauma patients: a review. J Trauma 44:908914, 1998

36. Rampersaud YR, Annand N, Dekutoski MB: Use of minimally invasive surgical techniques in the management of thoracolumbar trauma: current concepts. Spine (Phila Pa 1976) 31 (11 Suppl):S96-S104, 2006
37. Schinkel C, Frangen TM, Kmetic A, Andress HJ, Muhr G: Timing of thoracic spine stabilization in trauma patients: impact on clinical course and outcome. J Trauma 61:156-160, 2006

38. Schouten R, Ory K, Lee RS, Street JT, Boyd MC, Paquette SJ, et al: Health-related quality-of-life outcomes after thoracic (T1-T10) fractures. Spine J [epub ahead of print], 2013

39. Tator $\mathrm{CH}$ : Review of treatment trials in human spinal cord injury: issues, difficulties, and recommendations. Neurosurgery 59:957-987, 2006

40. Vaccaro AR, Daugherty RJ, Sheehan TP, Dante SJ, Cotler JM, Balderston RA, et al: Neurologic outcome of early versus late surgery for cervical spinal cord injury. Spine (Phila Pa 1976) 22:2609-2613, 1997

41. Vaccaro AR, Lehman RA Jr, Hurlbert RJ, Anderson PA, Harris M, Hedlund R, et al: A new classification of thoracolumbar injuries: the importance of injury morphology, the integrity of the posterior ligamentous complex, and neurologic status. Spine (Phila Pa 1976) 30:2325-2333, 2005

42. Wang PG, Vaccaro AR: Thoracolumbar spine fractures and dislocations, in Bucholz RW, Court-Brown CM, Heckman JD, et al (eds): Rockwood and Green's Fractures in Adults, ed 7. Philadelphia: Lippincott, 2010, Vol 2, pp 1377-1411

43. Weinstein JN, Collalto P, Lehmann TR: Thoracolumbar "burst" fractures treated conservatively: a long-term followup. Spine (Phila Pa 1976) 13:33-38, 1988

44. Whang PG, Vaccaro AR, Poelstra KA, Patel AA, Anderson DG, Albert TJ, et al: The influence of fracture mechanism and morphology on the reliability and validity of two novel thoracolumbar injury classification systems. Spine (Phila Pa 1976) 32:791-795, 2007

45. Wood K, Buttermann G, Mehbod A, Garvey T, Jhanjee R, Sechriest V: Operative compared with nonoperative treatment of a thoracolumbar burst fracture without neurological deficit. A prospective, randomized study. J Bone Joint Surg Am 85-A:773-781, 2003 (Erratum in J Bone Joint Surg Am 86A:1283, 2004)

46. Wood KB, Bohn D, Mehbod A: Anterior versus posterior treatment of stable thoracolumbar burst fractures without neurologic deficit: a prospective, randomized study. J Spinal Disord Tech 18 (Suppl):S15-S23, 2005

47. Wood KB, Li W, Lebl DS, Ploumis A: Management of thoracolumbar spine fractures. Spine J 14:145-164, 2014

48. Xing D, Chen Y, Ma JX, Song DH, Wang J, Yang Y, et al: A methodological systematic review of early versus late stabilization of thoracolumbar spine fractures. Eur Spine J 22: 2157-2166, 2013

49. Yazici M, Atilla B, Tepe S, Calisir A: Spinal canal remodeling in burst fractures of the thoracolumbar spine: a computerized tomographic comparison between operative and nonoperative treatment. J Spinal Disord 9:409-413, 1996

Manuscript submitted March 1, 2014.

Accepted May 6, 2014.

Please include this information when citing this paper: DOI: 10.3171/2014.5.FOCUS1473.

Address correspondence to: Christopher Paul O’Boynick, M.D., 7021B Heege Rd., Saint Louis, MO 63123. email: coboynic@slu. edu. 